\title{
AN UNUSUAL CASE OF EPIZOOTIC LYMPHANGITIS.
}

By Capt. E. E. Martin, A.V.D., Aldershot.

THE animal, a well-bred bay mare, was reported as having broken out with a number of pimples all over the body. The eruption appeared like very small boils, the heads of which, if picked off, showed tiny punched-out holes, from which a little serous fluid exuded. Several of these "boils" were connected by a very fine "cord."

I had the mare put by herself, kept under observation, and tested with mallein, the result of which was negative.

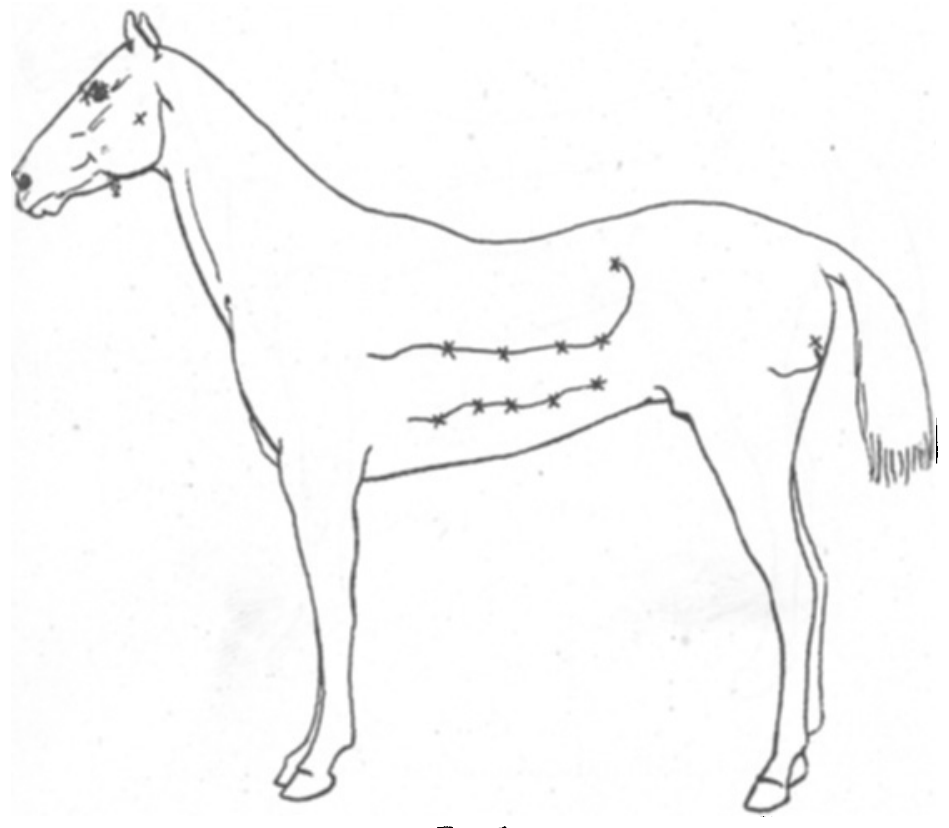

F1(.. 1.

To indicate the distribution of the lesions on the near side.

Those eruptions that had had their heads removed seemed to dry up at first, but in a few days' time I found matter was forming under the scabs, and, when I removed one and examined a speck of the fresh matter under the microscope, I found numbers of the cryptococci of Rivolta.

Treatment was considered inadvisable, so she was destroyed.

A day or two previous to destruction a discharge from the left eye was noticed, and on examination the haw was found to be perforated by an ulcer.

The animal was in excellent condition; the pulse, breathing, temperature, appetite, etc., were recorded twice daily, and no variation from the normal was detected the whole time she was under observation. 
Before destruction I made drawings of the situations of the lesions, which are here reproduced, and give an idea of the wide area over which they were scattered.

Post-mortem examination showed all the external organs healthy: On stripping the skin in the affected regions, it was found that the eruptions and cording were confined to the deep layers of the skin, and did not extend into the subcutaneous tissues. The cording was about the thickness of thin whipcord, and was very well defined.

The special point about this case is the simultaneous and widespread nature of the lesions, which is rather opposed to the generally

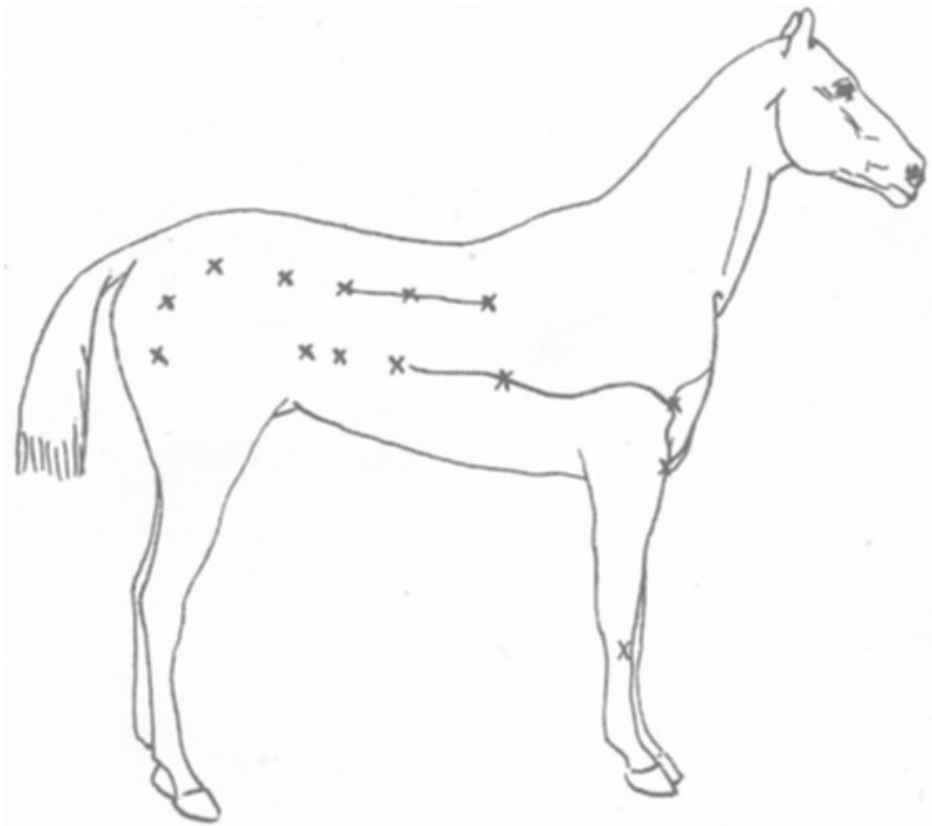

FIG. 2.

To indicate the distribution of the lesions on the off side.

accepted view that infection always takes place through some previous wound in the neighbourhood of the lesion.

One possible explanation occurs to me-viz., that there may have been some old infection which had remained in the form of an abscess, and that this had suddenly broken down and discharged the organisms into the circulation. Of course this is pure conjecture, and I could find no old lesion to support the theory.

I may add that the microscopical diagnosis was verified by several independent observers. 